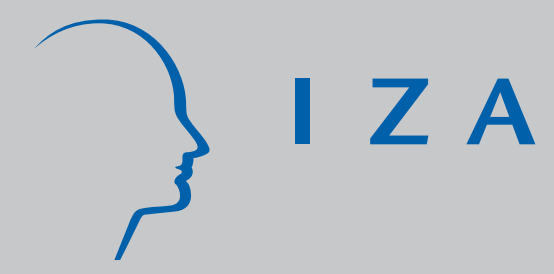

IZA DP No. 1786

Why Are Similar Workers Paid Differently?

The Role of Social Networks

François Fontaine

September 2005 


\title{
Why Are Similar Workers Paid Differently? The Role of Social Networks
}

\author{
François Fontaine \\ GREMARS, Université Lille 3 \\ and IZA Bonn
}

\section{Discussion Paper No. 1786 \\ September 2005}

\author{
IZA \\ P.O. Box 7240 \\ 53072 Bonn \\ Germany \\ Phone: +49-228-3894-0 \\ Fax: +49-228-3894-180 \\ Email: iza@iza.org
}

Any opinions expressed here are those of the author(s) and not those of the institute. Research disseminated by IZA may include views on policy, but the institute itself takes no institutional policy positions.

The Institute for the Study of Labor (IZA) in Bonn is a local and virtual international research center and a place of communication between science, politics and business. IZA is an independent nonprofit company supported by Deutsche Post World Net. The center is associated with the University of Bonn and offers a stimulating research environment through its research networks, research support, and visitors and doctoral programs. IZA engages in (i) original and internationally competitive research in all fields of labor economics, (ii) development of policy concepts, and (iii) dissemination of research results and concepts to the interested public.

IZA Discussion Papers often represent preliminary work and are circulated to encourage discussion. Citation of such a paper should account for its provisional character. A revised version may be available directly from the author. 


\section{ABSTRACT \\ Why Are Similar Workers Paid Differently? The Role of Social Networks*}

We provide a matching model where identical workers are embedded in ex-ante identical social networks. Job arrival rate is endogenous and wages are bargained. We study the evolution of networks over time and characterize the equilibrium distribution of unemployment rates across networks. We emphasize that wage dispersion arises endogenously as the consequence of the dynamics of networks, firms' strategies and wage bargaining. Moreover, contrary to a generally accepted idea, social networks do not necessary induce stickiness in unemployment dynamics. Our endogenous matching technology shows that the effects of networks on the dynamics mostly hinge on search externalities. Our endogenous framework allows us to quantify these effects.

JEL Classification: E24, J64, J68

Keywords: social networks, matching, wage dispersion

Corresponding author:

François Fontaine

GREMARS - Université Lille 3

B.P. 60149

59653 Villeneuve d'Ascq Cedex

France

Email: fontaine@ensae.fr

\footnotetext{
* I would like to thank Pierre Cahuc, Guy Laroque, Christopher Pissarides, Jean-Marc Robin, Fabien Postel-Vinay and Gilles Saint-Paul for their useful comments and suggestions. I am also grateful for valuable comments received from conference participants at Society of Economic Dynamics meeting 2004) and the European Economic Association (2004), and from seminar participants at CREST, Université d'Evry, Université Paris 1, Universités de Lille.
} 


\section{Introduction}

Observable workers' characteristics account for only one third of the variation in compensation across workers (Katz and Autor, 1999, Mortensen, 2003). In a recent paper, Postel-Vinay and Robin (2003) have shown that the previously unexplained variance could be decomposed between unobserved workers' productive heterogeneity, firms' heterogeneity and the effects of search frictions. While in their model and estimations all workers having the same employment status face the same job arrival rate, Bowlus (1997) has demonstrated that wage differential could be due to differences in labor market search behavior patterns, i.e. differences in the job arrival rates. Eventually, she estimates that this heterogeneity accounts for a large part of wage differential (between 20 and 30\%). In our paper, we aim at providing a theoretical counterpart of wage dispersion that comes from search frictions and inequalities in arrival rates of job offers due to social networks.

The role of social networks has been recognized for a long time by sociologists ${ }^{1}$ and it is now well known that a large proportion of people (between one third and two third) hear about or obtain jobs through friends and relatives (e.g. Rees, 1966, Granovetter, 1995, Holzer, 1988, Montgomery, 1991, Topa, 2000, for the U.S., Addison and Portugal, 2001, for Portugal). However, the empirical link between social networks and wage dispersion is ambiguous. For instance, Holzer (1987), Simon and Warner (1992) and Petersen et al. (2000) find that employees who get their job through social networks have higher earnings, while Hurbelt and Mardsen (1988), find little impact of job finding method on wages. Kugler (2003), using the NLSY, shows that the wage premia for referred workers becomes insignificant once sector of employment is controlled for. Eventually, Bentolila et al. (2003) provide empirical evidences that networks generate mismatch between workers and vacancies, leading to a negative relationship between the use of social networks and wages.

In this paper, we consider an homogeneous labor force in order to study the within group wage variance that only comes from the fact that social networks entail heterogeneity in job arrival rates. The lower the number of unemployed workers in a network, the higher the probability for the remaining unemployed to receive an offer through the network. Indeed, the number of employees defines the number of potential sources of information about job offers. Consequently, if the unemployment rates differ across networks, job seekers face different job arrival rates, depending on the state of their network.

In economics, some contributions have already underscored the role of social networks in the information structure of job findings. Boorman (1975) was the first to provide a formal model where individuals can get job offers through friends and relatives. More recently Montgomery (1991), Calvo-Armengol and Zenou (2002), Bentolila et al. (2003), Cahuc and Fontaine (2003), and Fontaine (2004) analyze the effects of social contacts on the efficiency of labor market. Nevertheless, few papers try to link wage dispersion with networks. To our knowledge Mortensen and Vishwanath (1994) were the first to study it, but in a context where wage dispersion does not depend on the existence of networks, the arrival rate of the job offers exogenous and where the use of friends and relatives is represented by the fact that at a given rate unemployed receive wage offers drawn from the distribution of wages earned by employed workers. We aim at providing a more general framework where the only source of wage dispersion is the social networks. Moreover, we also want to be able to study and quantify their effects on the

\footnotetext{
${ }^{1}$ See Granovetter (1995) and the references therein.
} 
unemployment persistence or the spatial inequalities. Calvo-Armengol and Jackson (2004a) have developed a model where the structure of networks is explicitly modeled and studied the effect of the networks dynamics on unemployment dynamics and wages. However, in their paper, the labor market is black-boxed. Indeed, wage dispersion exists ex-ante and job offer arrival rate is exogenous.

Our main contributions are the followings. First, we provide a matching model where wage dispersion arises endogenously as the consequence of the joined dynamics of networks, firms' strategies and wage bargaining. Ex-ante identical networks evolve with time and we derive the equilibrium distribution of unemployment rates. Our model emphasize that the inequality of unemployment rates produces heterogeneity in the job arrival rates. Indeed, the probability to get an offer hinges on the number of employees. In an endogenous wage setting framework, a higher job arrival rate strengthens the outside opportunities of workers and thus affects his wage. Hence, the distribution of employment across networks induces wage dispersion. Then, we compute the stationary aggregate distribution of networks and wages for two countries, the United States and France, in order to check in what extent our model generate wage dispersion.

Then we study the dynamics of networks' unemployment rates and how social networks can induce unemployment persistence. In comparison with Calvo-Armengol et Jackson (2004a), our endogenous model sheds some new lights on this issue. Networks induce correlation between agents' statuses but this correlation does not necessarily induce stickiness in the employment dynamics. We show that the effect of networks on unemployment persistence mostly hinges on search externalities. On the one hand, the individuals benefit from the search intensity of employees in their network. On the other hand, the fact that employees also search for a job (for their unemployed friend) entails an increase in congestions on the labor market. For a given network, the overall effect depends on the number of employees. For the most disadvantaged networks, we show that social networks induce that the time needed to reach the average unemployment rate is twice larger in comparison with an economy where only formal methods of search exist.

The model, the equilibrium distribution of networks and wages are presented in section 2 . Section 3 is devoted to a quantitative evaluation of wage variance induces by networks while section 4 studies their effect on unemployment dynamics and wage profile.

\section{Heterogenous social networks}

\section{The framework}

The basic environment borrows from Pissarides (2000) matching model of the labor market. An endogenous number of competitive firms produce a numeraire output, using labor as sole input. There is a large labor force which size is denoted by $N$. We assume that all workers have the same productivity $y$ and that an employee faces an exogenous destruction rate $q$. Moreover, an unemployed benefits from an income flow $z$. Time is continuous, individuals are infinitely lived, risk neutral and discount the future at rate $r>0$.

Hiring a worker and searching for a job are costly activities. Vacant jobs and unemployed workers are brought together in pairs through an imperfect matching process. We assume that the unemployed workers and the employees search for a job. However, the employees are looking for a job for their unemployed friends and not for themselves. If an employee receives a job offer, 
he forwards it towards its unemployed friends. We consider an economy where each individual belongs to a network of friends and relatives and we assume that individuals are embedded in complete networks of size $\ell$. A complete network is a network where all agents are linked together. Thus, each individual belongs to a network of $\ell$ members including himself.

Let us denote by $s_{u}$ (respectively $s_{e}$ ) the intensity of search of the unemployed workers (respectively the efforts made by the employees to find a job for their unemployed friends). Accordingly, job offers meet job seekers at a rate

$$
M\left(N u s_{u}+N(1-u) s_{e}, V\right)
$$

with $V$ the number of vacant jobs ( $v$ the vacancy rate $v=V / N)$ and $u$ the unemployment rate. Let us note that, in our model, the matching rate is not the rate at which a job offer is received by an unemployed, but the rate at which a job offer reaches the labor market. Especially, an offer can be received by an employee with no unemployed in its social network. In this case, we assume that the offer is lost. As usual, the matching function is assumed concave, increasing in both its arguments . Let us remark, that the matching rate increases with $u$ if $\left(s_{u}-s_{e}\right)>0$, that is if the search intensity of unemployed is higher than the intensity of search of employees looking for a job for their unemployed friends. It is worth noting that our matching function could be based on an urn-ball process where each vacancy is a ball that is send into urns representing the workers (the unemployed workers and the employees). We offer in Appendix an example of such urn-ball process. However, in this paper, we decide to consider a more general framework and not base directly our matching function on an urn-ball process.

In our model, both search intensities are assumed exogenous. The reason why the employees help their unemployed acquaintances is a very interesting point, but beyond the scope of this paper. A self-interested agent can forward an offer if he expects that the helped individual will help him in the future or if he expects that this could improve his social position. If the expected payoff of cooperation is related to future job search (for example in case of a job loss), it can also be related to something outside the labor market. For example, it could be affected by social conventions, social group's traditions or social prestige. Here, we assume implicitly that the level of cooperation between the employees and the unemployed workers (represented by the search intensity of the employees $s_{e}$ ) is a social norm from which the individuals cannot deviate ${ }^{2}$.

In much of the labor market models which take into account the existence of the social networks, it is usual to assume implicitly that the individuals are re-matched at random with $\ell$ links just after every job arrival (Boorman, 1975, Calvo-Armengol and Zenou, 2002, Cahuc and Fontaine, 2003). On the contrary, we assume here that the individuals always keep the same acquaintances. However, the status of these acquaintances on the labor market evolves over time and there is a distribution of unemployment rates across networks. This feature is more realistic than the previous assumptions even if it is only a limit case since we do not take into account the problem of networks' formation. However, remark that, in real life, the possibilities for the individuals to choose their acquaintances are only limited since the social contacts relevant for the job search are the output of a process where the level of education, the gender and the

\footnotetext{
${ }^{2}$ For example, the cooperation could be sustained by the following strategy: if an employee deviates and refuses to make an effort to find a job for his unemployed friend, the other members of its social network exclude him from the network. Consequently, this employee, if his job is destroyed, will find a job only if he receives an offer directly.
} 
social origins play a large role. From a more practical point of view, the theoretical literature on endogenous networks does not offer any simple way to deal with strategic network formation process and even the available results (e.g. Jackson and Watts, 2002, Page et al., 2005, and Dutta et al., 2005) are still too general to be used together with an equilibrium model of the labor market.

\section{The exit rate from unemployment}

We denote by $n$ the number of employees in a given network. Every network can be in $\ell+1$ different states, namely, $n \in\{0,1,2, \ldots, \ell\}$. In our framework, the evolution of a network is a continuous-time Markov chain with states $\{0,1,2, \ldots, \ell\}$ for which transitions from state $n$ may go only to either state $n-1$ (if an employee of the network looses his job) or state $n+1$ (if an unemployed find a job). The probability that this chain will be in state $n$ at time $t$ converges to a limiting value, denoted by $\pi(n)$ which is independent of the initial state. We denote by $\Pi$ the stationary distribution.

By assumption, the employees transmit informations about job offers. According to our matching function, the probability to find a job per efficiency unit of search reads

$$
\lambda(u, v)=\frac{M\left(u s_{u}+(1-u) s_{e}, v\right)}{u s_{u}+(1-u) s_{e}}
$$

When an employee finds an offer ${ }^{3}$, he forwards this offer toward one of his unemployed friend. If there is more than one unemployed worker in the network, they all get the same probability to obtain the job offer. Hence, an unemployed worker belonging to a network with $n$ employees, meets a vacant job at a rate $R(n, u, v)$ for $n \in\{0, \ldots, \ell-1\}$ :

$$
R(n, u, v)=\lambda(u, v)\left(s_{u}+s_{e} \frac{n}{\ell-n}\right)
$$

This individual arrival rate is an increasing convex function in the number of employees. Indeed, an higher number of employees induce an higher search in the network and a lower number of workers looking for a job.

\section{The distribution of the networks}

A network can be in $\ell+1$ different states. We denote by $X$ the matrix describing the transition between the states. The $(i, j)$ element of the matrix is the probability that a network goes from state $i$ to state $j$ within an infinitesimal period of time: $x(i, j)=P(n(t+d t)=j \mid n(t)=i)$ when $d t$ goes to zero. Accordingly, $x(i, i-1)=q i d t, x(i, i+1)=R(i, u, v)(\ell-i) d t$ and $x(i, i)=1-q i d t-R(i, u, v)(\ell-i) d t$. A stationary distribution satisfies

$$
\Pi^{\prime} X=\Pi^{\prime}
$$

with $\Pi=\{\pi(0), \ldots, \pi(\ell+1)\}$ the vector of probabilities to be in state $i$ at the steady state. The flow equilibrium conditions of our Markov chain between each state of the system reads:

$$
\left\{\begin{array}{c}
\pi(0) R(0, u, v) \ell=q \pi(1) \\
\cdots \\
q i \pi(i)+\pi(i) R(i, u, v)(\ell-i)=q(i+1) \pi(i+1)+(\ell-i+1) \pi(i-1) R(i-1, u, v) \\
\cdots \\
q \times \ell \times \pi(\ell)=\pi(\ell-1) R(\ell-1, u, v)
\end{array}\right.
$$

\footnotetext{
${ }^{3}$ In a continuous framework a worker can received only one offer within the same period of time.
} 
Solving the system in term of $\pi(0)$ and using the fact that $\sum_{n} \pi(n)=1$, one gets:

$$
\pi(n)=\frac{\prod_{i=0}^{n-1} \frac{(\ell-i) R(i, u, v)}{q(i+1)}}{1+\sum_{j=1}^{\ell} \prod_{i=0}^{j-1} \frac{(\ell-i) R(i, u, v)}{q(i+1)}}
$$

In the next sections, without loss of generality, we consider the case where $s_{u}=1$ and $s_{e} \leq s_{u}$. Accordingly, (2), the individual arrival rate of the job offers, reads, for $n \in\{0, \ldots, \ell-1\}$ :

$$
\begin{aligned}
R(n, u, v) & =\frac{M\left(u+(1-u) s_{e}, v\right)}{u+(1-u) s_{e}}\left(1+s_{e} \frac{n}{\ell-n}\right) \\
& =\lambda(u, v)\left(\frac{\ell-\left(1-s_{e}\right) n}{\ell-n}\right)
\end{aligned}
$$

Eventually, remark that, according to the flow equations (3) and with $\pi(n)$ defined by (4), the unemployment rate at the steady state reads ${ }^{4}$ :

$$
u=\sum_{i=0}^{\ell-1} \frac{\ell-i}{\ell} \pi(i)
$$

\section{Expected utilities, profits and wages}

We consider an economy at the steady state. All firms are identical. Wages are bargained by the firm and the worker after they meet and can be renegotiated each period at no $\operatorname{cost}^{5}$. The individual arrival rate of a job offer, in a given network, hinges on the number of employees in the network, $n$. Consequently, this number defines the outside opportunities of the workers and wages can depend on $n$. When a firm contacts an unemployed worker who belongs to a network with $n$ employees, it hires this worker. Consequently, the network switches from state $n$ to state $n+1$. Let us denote by $U(n)$ the value function of an unemployed worker in a network where there are $n$ employees and $E(n+1)$ the value function of an employee in a network of $n+1$ employees. Let us remark that the individuals only differ as regards the number of employees in their network. $U(n)$ satisfies for $n \in\{0, . ., \ell-1\}$ :

$$
r U(n)=\left\{\begin{array}{l}
z+R(0, u, v)(E(1)-U(0))+(\ell-1) R(0, u, v)(U(1)-U(0)) \\
\text { for } n=0 \\
z+R(n, u, v)(E(n+1)-U(n))+(\ell-n-1) R(n, u, v)(U(n+1)-U(n)) \\
+q n(U(n-1)-U(n)) \text { for } n \in\{1, . ., \ell-2\} \\
z+R(\ell-1, u, v)(E(\ell)-U(\ell-1))+q(\ell-1)(U(\ell-2)-U(\ell-1)) \\
\text { for } n=\ell-1
\end{array}\right.
$$

\footnotetext{
${ }^{4}$ Offers can reach an employee that belongs to a network without unemployed worker. In this case, we assume that the offer is lost. This is due to our hypothesis that every employee has the same search intensity $s_{e}$. The reason could be that the search for a job is a long-term activity and that it is difficult for an individual to change its search intensity at each period. Even if there is not any unemployed worker in the network, an employee could take into account that the state of the network evolves with time and that one of his friend could loose his job in the future.

${ }^{5}$ While usual in the labor market matching litterature, this hypothesis is restrictive. However, it offers a convenient way to reduce the analytical complexity of the model. We discuss at the end of this section the informational assumptions.
} 
Consider an unemployed worker in a network with $n$ employees. At a rate $R(n, u, v)$ he finds a job and becomes employee. Moreover, the network switches from state $n$ to state $n+1$. Besides, with a probability $(\ell-n-1) R(n, u, v)$, one of his unemployed worker gets a job and, next period, the network will be in state $n+1$ while the worker we consider remains unemployed. Eventually, if an employee is fired, an event that occurs at a rate $q n$, the network switches from state $n$ to state $n-1$. In the same way, the value function of an employee $E(n+1)$ satisfies

$$
r E(n+1)=\left\{\begin{array}{l}
w(1)+(\ell-1) R(1, u, v)(E(2)-E(1))+q(U(0)-E(1)) \\
\text { for } n=0 \\
w(n+1)+(\ell-n-1) R(n+1, u, v)(E(n+2)-E(n+1)) \\
+q n(E(n)-E(n+1))+q(U(n)-E(n+1)) \text { for } n \in\{1, . ., \ell-2\} \\
w(\ell)+q(\ell-1)(E(n)-E(n+1))+q(U(n)-E(n+1)) \\
\text { for } n=\ell-1
\end{array}\right.
$$

An employee in a network with $n+1$ employees (including himself) is paid $w(n+1)$. His job is destroyed at a rate $q$ per unit of time but we also have to take into account that one of his friend can also become unemployed. In both case, the network switches from state $n+1$ to state $n$. Moreover, an unemployed worker of his network can find a job. Accordingly, the network switches from state $n+1$ to $n+2$ at a rate $(\ell-n-1) \times R(n+1, u, v)$.

We denote by $J(n+1)(n \in\{0, . ., \ell-1\})$ the value of a filled position for a firm with a worker in social network with $n+1$ employees (including himself). Replication of previous reasonings implies, with $V A$ the value of a vacant job,

$$
r J(n+1)=\left\{\begin{array}{l}
y-w(0)+(\ell-1) R(1, u, v)(J(2)-J(1))+q(V A-J(1)) \\
\text { for } n=0 \\
y-w(n+1)+(\ell-n-1) R(n+1, u, v)(J(n+2)-J(n+1)) \\
+q n(J(n)-J(n+1))+q(V A-J(n+1)) \text { for } n \in\{1, . ., \ell-2\} \\
y-w(\ell)+q(\ell-1)(J(\ell-1)-J(\ell))+q(V A-J(\ell)) \\
\text { for } n=\ell-1
\end{array}\right.
$$

Consider an employee in a network with $n+1$ employees. A job is destroyed at a rate $q$. Thus at a rate $q n$ one of his employed friend looses his job and the network goes from state $n+1$ to state $n$. On the contrary, with a probability $(\ell-n-1) R(n+1, u, v)$ an unemployed worker of the network finds a job and the network goes from state $n+1$ to state $n+2$.

Now, consider a job offer. If the offer is received by a network where everybody has a job, we assume that it is lost. The probability for an offer to reach a type- $n$ network amounts to the share of the type- $n$ networks search intensity in the total amount of search effort. Thus, this probability, denoted by $\kappa(n, u, v)$, reads:

$$
\kappa(n, u, v)=\underbrace{\left(n s_{e}+(\ell-n)\right)}_{\begin{array}{c}
\text { Search intensity of } \\
\text { networks with } \\
n \text { employees }
\end{array}} \times \underbrace{\pi(n, u, v)}_{\begin{array}{c}
\text { Share of } \\
\text { type } \mathrm{n} \\
\text { network }
\end{array}} \times \frac{1}{\sum_{i=0}^{\ell}\left(i s_{e}+(\ell-i)\right) \pi(i, u, v)}
$$

and $V A$, the value of a vacant job, satisfies:

$$
r V A=-h+\frac{M\left(u+(1-u) s_{e}, v\right)}{v} \sum_{i=0}^{\ell-1}(J(i+1)-V A) \times \kappa(i, u, v)
$$


with $h$ the vacancy cost and $M\left(u+(1-u) s_{e}, v\right) / v$ the contact rate between the job offer and the labor market. Let us remark that we take into account the expected profit that, if the offer reaches a network where there is no unemployed, the vacancy remains unfilled.

\section{The decentralized equilibrium}

It is assumed that all profit opportunities from a new job are exploited. Accordingly, jobs are created until the expected value of vacancies goes to zero $(V A=0)$. Accordingly, using $(9)$ and (10) one gets the following condition for the decentralized equilibrium:

$$
\frac{h v}{M\left(u+(1-u) s_{e}, v\right)}=\sum_{n=0}^{\ell-1} J(n+1) \times \kappa(n, u, v)
$$

Wages are subject to bargaining between the firm and the worker and are renegotiated each period. It is worth noting that our bargaining process implies perfect information about worker's type and thus the state of his network. To what extend wage dispersion survives incomplete information during the bargaining process? First, one could consider that, in real life, firms have indirect information about the outside opportunities of workers. Indeed, social networks are distributed over space. Most of the time, the employer knows the address of the applicant and thus can infer the type of social network he belongs to. For example, if he comes from a disadvantaged neighborhood, the employer will expect a small probability for the worker to be helped during his job search by friends and relatives. Besides, game theoretical literature shows that, with incomplete information during bargaining and heterogeneity between players ${ }^{6}$, strategic delays between offers and counteroffers are used by agents to communicate their types (Admati and Perry, 1987, Gul and Sonneschein, 1988, Cramton, 1992). Formally, individuals with a high outside option (here a high job arrival rate) does not accept the first firm's offer and delays counteroffer long enough to separate themselves from low types workers. This results holds even when the minimal time between offers becomes arbitrary small (Admati and Perry, 1987). Accordingly, even with asymmetric information about workers' types, the wage would hinge on the employment rate within the worker's network. In this article, we use the standard Nash solution of games with perfect information to reduce the complexity of the model. We denote by $\beta \in[0,1]$ the share of the surplus that accrues to workers. Assume that a firm and a worker who belongs to a network with $n$ other employees bargain over the wage, the Nash solution reads, for $n \in\{0, \ldots, \ell-1\}$ :

$$
(1-\beta)(E(n+1)-U(n))=\beta J(n+1)
$$

Remark that (12) defines $\ell$ equations. Besides equations (7), (8) and (9) represent a system of $3 \times \ell$ nonlinear recurrence equations that cannot be solved analytically for $U(n), E(n+1)$ and $J(n+1)$.

Accordingly, the decentralized equilibrium is a vector $\{u, v, w(1), \ldots, w(\ell), U(0), \ldots, U(\ell-$ $1), E(1), \ldots, E(\ell), J(1), \ldots, J(\ell)\}$ of $4 \times \ell+2$ unknowns that have to satisfy a system of $4 \times \ell+2$

\footnotetext{
${ }^{6}$ In this framework, the employer has usually no initial information on worker's type but knows the distribution of type among workers.
} 
equations:

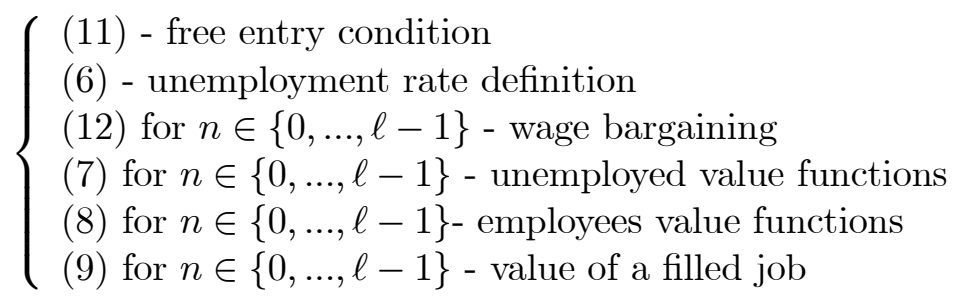

\section{Do the social networks matter?}

How does the existence of social networks affects the wage distribution? What is the quantitative impact of networks on unemployment persistence and employment histories? Some studies have proposed economic policies designed to take into account the existence of social networks (see for example Cahuc and Fontaine (2003), Calvo-Armengol and Jackson (2004), Fontaine (2004)). However, the empirical effects of social networks on unemployment persistence and wage distribution are not clear. On the one hand, the use of social networks increases the job arrival rate of individuals. On the other hand, networks could induce misallocation of workers across occupations.

In this paper, we aim at providing an evaluation of networks' effects on the within group wage dispersion and unemployment dynamics. Especially, we want to show that networks can induce wage dispersion even if workers, jobs and networks' sizes are identical. For that reason, we only consider the effects that come from differential in the arrival rate of jobs offers and not the possible productivity biases in networks composition (e.g. Montgomery, 1991, Bentolila et al., 2003) or the fact that networks could be a screening device for recruiters (Fernandez et al., 2000). In this section, we calibrate the stationary aggregate distribution of networks and wages for two economies, the United States and France. We show that social networks may generate a significant wage variance.

\section{Calibration}

We take the period to be one day. Indeed, we have previously assumed that more than one event can not occur during the same period. Such an assumption, implicit in most of the matching models (see Mortensen and Pissarides, 1999), is important here. Indeed, we have to compute the transition of networks embedding a lot of workers (see (3)). Thus, we have to consider during our simulations a sufficiently small period of time in order to guarantee that, for a reasonable network size, the probability that a network goes from state $i$ to state $j$ stands between 0 and 1 .

Assume an homogenous matching function of degree one $M() / N=.A \times\left(u s_{u}+(1-\right.$ $\left.u) s_{e}\right)^{\alpha} v^{1-\alpha}$, with $A$ an efficiency parameter. The productivity of a new job is normalized at unity and, as it is usually done in the matching literature, we consider that the elasticity parameter $\alpha$ and the bargaining power of the employees amounts to $.5^{7}$.

We first base our calibration on the US monthly flows reported in Wasmer and Garibaldi (2003). These flows are computed using the CPS data for the 15-64 population between February

\footnotetext{
${ }^{7}$ Usually $\alpha$ is set to satisfy the Hosios condition for social efficiency (see Petrongolo and Pissarides, 2001). In our model the elasticity of the matching function as regards unemployment amounts to $\alpha\left(1-s_{e}\right)$. However, we do not have estimations of this kind of matching function. Consequently, we prefer to take the usual value for this parameter.
} 
1994 and November 2000. We use these monthly statistics to compute a daily destruction rate. For example, the probability for a worker to lose his job during a month is $1.55 \%$ in the United States. If the probability of job destruction is exponentially distributed, $q$ is such as $1-e^{-q \times 30}=1.55 \%$.

In the same way, we calibrate the daily interest rate $r$ using information on the monthly interest rate $\left(\left(1+r_{\text {month }}\right)^{1 / 30}=1+r_{\text {day }}\right.$, with $\left.r_{\text {month }}=.5 \%\right)$. We set the daily search cost of firm to represent $30 \%$ of the productivity of an employee during the same period of time to be consistent with survey results reported by Hamermesh (1993). The value of leisure amounts to .15. Eventually the efficiency parameter $A$ is calibrated to reproduce an unemployment rate of $4.5 \%$, the average unemployment rate in the US during the second half of the nineties.

The social networks are summarized by two parameters $s_{e}$ and $\ell$. Empirical evidences show that between one third and two thirds of the unemployed find their jobs through networks (e.g. Montgomery, 1991, and the survey of Granovetter, 1995). During the simulations the search intensity of the employees $s_{e}$ is set in order that one half of the jobs are found through networks. As regards the number of links, some empirical studies are devoted to the evaluation of the number of acquaintances that a typical person possesses (Bernard et al., 1989, 2001). However, it is difficult to know what is the relevant definition of an acquaintance when one studies the labor market. Indeed, the relevant links are not only the strongest (for example our close friends) but also the weakest one (Granovetter, 1995) which are more diversified. Besides, the method used in these studies has revealed deep problems. First, when these studies are based on a survey, it is obvious that people are quite poor at estimating their number of friends and that the number reported by the individual is highly sensitive to the definition they have of a "meaningful" contact. Besides, when we use more indirect estimation method, we face the same problem, that is the definition of the relevant relationships ${ }^{8}$. In this section, we assume that the number of individuals $\ell$ in each network amounts to 40. This is a pretty low number with respect to the empirical evidences but we show in Appendix that an increase of this number would not change our result. We only try to provide a value which is realistic and limit the size of networks for computational reasons. Our calibration is reported in Table 1.

\begin{tabular}{cccccccccc} 
Parameters & $y$ & $h$ & $z$ & $s_{u}$ & $\beta$ & $\alpha$ & $\ell$ & $r$ & $q$ \\
\hline \hline Values & 1 & .3 & .15 & 1 & .5 & .5 & 40 & .00016 & .0005 \\
Tab. 1 & Calibration for the US economy
\end{tabular}

Do the effects of the social networks hinge on the level of the unemployment in the economy? It is possible that, in a low unemployment rate economy, social networks do not play a large role since all networks are in a good state. In an economy where the unemployment rate is higher, an unemployed belonging to an efficient network with a large number of employees has a comparative advantage. Such a mechanism could induce a positive correlation between the level of unemployment rate and wage dispersion. To test this assertion, we also make our simulation with a set of parameters representing the French economy during the nineties. The $\left\{y, h, s_{u}, \beta, \ell, r\right\}$ parameters do not change. The value of leisure is set to .4. Interpreted as unemployment benefit, this gives a replacement ratio consistent with the French ratio (about 50\%). Cahuc et al. (2003) have estimated on French data that the yearly destruction rate ranges between .03 and .1. In our simulation, the destruction rate $q$ is assumed to be 0.002 to

\footnotetext{
${ }^{8}$ See D.J. Watts (1999) for an useful survey of the existing litterature.
} 
match the typical value of .07 in yearly rate. Eventually, we choose $A$ to reproduce the average empirical unemployment rate of $10 \%$.

\begin{tabular}{cccccccccc} 
Parameters & $y$ & $h$ & $z$ & $s_{u}$ & $\beta$ & $\alpha$ & $\ell$ & $r$ & $q$ \\
\hline \hline Values & 1 & .3 & .4 & 1 & .5 & .5 & 40 & .00016 & .0002 \\
Tab. 2 & - Calibration for the French economy &
\end{tabular}

\section{The distribution of wages}

Factors like sex, education and experience account for only one third of overall wage dispersion (Katz and Autor, 1999, Mortensen, 2003) and numerous papers have tried to explain the residual dispersion. Bowlus (1997) has already provided a model together with an econometric estimation where the wage differential is due to differences in labor market search behavior patterns. These differences are represented in her model by different arrival rates. Eventually, she estimates that this heterogeneity induces a large wage differential. In our model, we propose a micro-foundation for arrival rate differential between ex ante identical individuals based on the inequality of the unemployment rate between networks. We thus provide a theoretical counterpart of the well-documented within group empirical wage dispersion (Katz and Autor, 1999).

In our framework, if $s_{e}=0$ we get the standard matching model. In this case, all individuals are paid at the same wage rate, whatever the unemployment rate in their network. All individuals are identical as regards productivity. Hence, the existence of a wage distribution only hinges on the fact that two networks can be in different states inducing differences in job arrival rates. It is worth noting that ex ante all networks are identical. Nevertheless, the random matching process implies that the networks have different histories on the labor market. The state of a network at a given period is the result of its history and this state induces a particular job offer arrival rate $R(n, u, v)$ for the workers in the network (Figure 1).

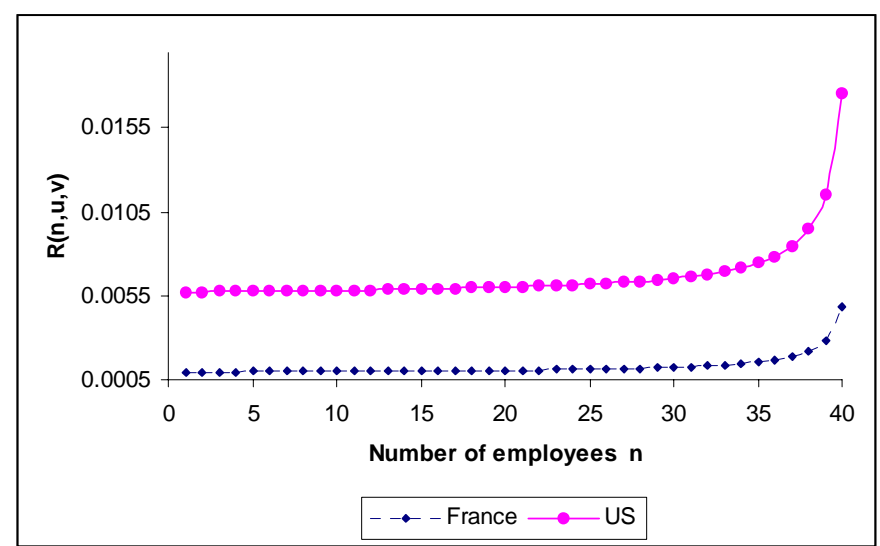

Figure 1 : The probability for an unemployed to get an offer $R(n, u, v)$, as a function of the number of employees in his network.

Let us remark that we do not aim at reproducing the shape of the empirical wage distribution. We try to investigate to what extent the network informational effect could induce wage dispersion and shape the distribution without any other source of heterogeneity. We first 
display the networks' distributions for $40 \geq n \geq 20^{9}$ and the relation between wages and the number of employees (Figure 2). Remember that the mean of employees distribution is $\ell(1-u)$ ( $u=.045$ for the US, .1 for France). Workers are concentrated at the right of the distributions around the aggregate employment rate and the probability that a randomly chosen network has an employment rate less that $50 \%$ is close to zero.

Notice that an interpretation of our results is that social networks induce a spatial dispersion of the employment rates, even if workers are identical. This point has already been pointed out in an empirical work by Topa (2001). We provide a theoretical counterpart to this statement.
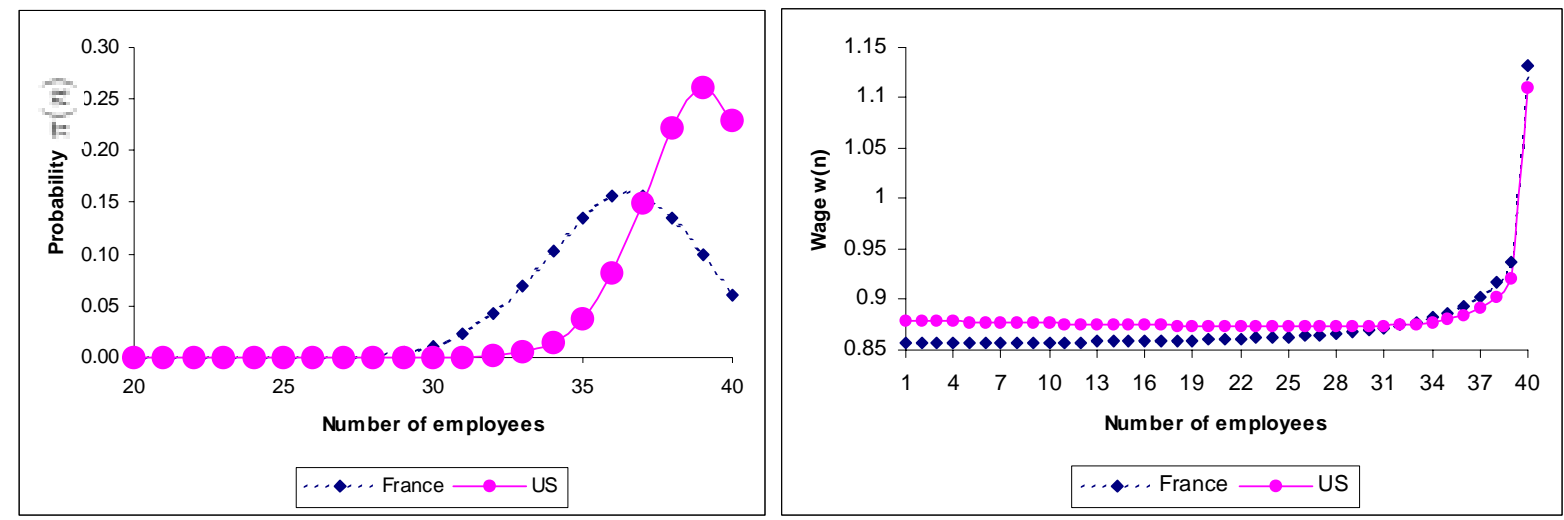

Figure 2: Networks Distribution and Wage Function

The social networks have different histories on the labor market and consequently differ in their states (number of employees) at a given period of time. This induces heterogeneity since the individual arrival rate is related to the number of contacts that are able to forward an offer (Figure 1). With a Nash bargaining rule, a higher probability to get a job induces a priori a higher wage by increasing outside opportunities. If two individuals belong to different networks, they probably do not face the same probability to get a job. Since the wage depends on the individual arrival rate of job offers, they are not paid the same wage. This simple mechanism produces wage dispersion that does not come from productive heterogeneity.

It is worth noting that, while workers' value functions always increase with the number of employees $n$, the wages can decrease with $n$ for networks which suffer from a low employment rate. Indeed, on the one hand, the arrival rate increases with $n$. This strengthens the bargaining power of the workers. Nevertheless, a worker embedded in a network with few employees can accept low wages since he takes into account that by becoming employed he allows his network to leave the worst states of the distribution more easily. If his network succeeds in increasing its employment rate, this worker will be paid more in the long run. This mechanism increases the threat point of the employer and explains why for low $n$, wages could decrease slightly with the number of employees. The wage distributions are displayed in Figure 3.

\footnotetext{
${ }^{9}$ For $n \leq 20, \pi(n)$ is positive but close to zero. For readability, the graph is restricted to $40 \geq n \geq 20$.
} 


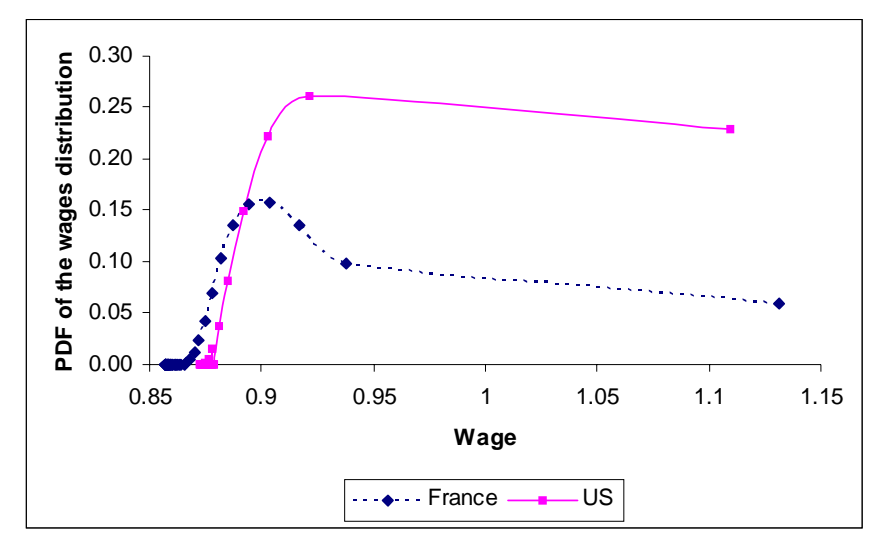

Figure 3: Wage Densities

The mean of the distribution is 0.95 for the US, .91 for France. The standard deviations, respectively .087 for the US and .058 for France, represent $9.2 \%$ and $6.4 \%$ of the mean wages. The dispersion induced by social networks is thus significant considering that the only source of heterogeneity comes from differences in the job arrival rate.

Let us remark that the wage profile is almost flat until the number of employees goes beyond the average one (see Figure 2). This is mostly due to the fact that the probability to get an offer is convex in the number of employees (see Figure 1). Consequently, it is mostly the workers embedded in networks with the highest employment rates who benefit from social links. The highest wage is $19 \%$ higher than the mean wage for France, $16 \%$ for the US.

Eventually, let us remark that, in our framework, the wage can be greater than the productivity of an employee. Indeed, the wage bargaining can induce a wage higher than the productivity of labor if the firm expect that it is only temporary. The existence of frictions on the labor market implies that searching for an applicant is a costly process. The firm can not fire an employee and instantaneously finds a worker for the vacant position. Consequently it can prefer to keep the worker knowing that the real wage will decrease in the future.

\section{Networks' dynamics and unemployment persistence}

The lower the number of employees, the lower the probability to find a job. Calvo-Armengol and Jackson $(2004 \mathrm{a}, \mathrm{b})$ have claimed that this simple mechanism, based on correlation between statuses, could induce unemployment persistence and explain the observed spatial correlation of unemployment rate (for example Topa, 2001). We study how our endogenous framework sheds some new lights on this issue.

\section{Do unemployed workers really benefit from social networks?}

Since the probability for an unemployed worker to get a job hinges on the number of employees in his network, the status of linked agents is correlated. An unemployed worker $i$ is more likely to get a job if his friend $j$ is employed. This state dependence could induce unemployment persistence. The higher the unemployment rate in a network, the lower the probability that this rate increases in the next period. Calvo-Armengol and Jackson (2004a) have already shown that networks could induce stickiness in the dynamics of employment. However they consider a job 
finding process where the arrival rate of informations about vacancies is completely exogenous. Especially, they do not consider that networks modify the matching technology. In an equilibrium framework, networks could increase the aggregate matching rate and thus accelerate the convergence towards the average rate of networks initially with a low employment rate.

First, we aim at understanding to what extent the unemployed workers benefit from the search effort of the employees, taken $u$ and $v$ as given. Indeed, the search effort of the employees strengthens the congestion on the labor market. This congestion effect represents the rivalry between the networks to get informations about job offers. While the unemployed members of a given network benefit from the search effort of their employed friends, they suffer from the search of the other employees who are looking for a job for their acquaintances. Formally, the probability to find a job $\lambda(u, v)$ per efficiency unit of search is a decreasing function in $s_{e}$. The derivative of the individual arrival rate of a job as regards $s_{e}$, taken $u$ as given, reads:

$$
\frac{\partial R(n, u, v)}{\partial s_{e}}=\underbrace{\frac{\partial \lambda(u, v)}{\partial s_{e}}\left(1+s_{e} \frac{n}{\ell-n}\right)}_{<0}+\underbrace{\frac{n}{\ell-n} \lambda(u, v)}_{>0}
$$

Remark that, for $n=0$, a marginal increase in $s_{e}$ leads to a decrease in the job arrival rate. In a network with a small number of employees the positive effect of the rise in $s_{e}$ is offset by the decrease in $\lambda(u, v)$. On the contrary, in a network with a larger number of employees the aggregate congestion effect is counterbalanced by the higher search effort of the network's employees. Consequently, taken $u$ and $v$ as given, the exit rate from unemployment of the individuals in networks with high unemployment rates would be higher in an economy without networks. This is not due directly to the correlation between statuses but to congestion externalities that the framework of Calvo-Armengol and Jackson cannot capture.

\section{Do networks induce unemployment persistence?}

Consider a subpopulation of workers with a high unemployment rate. If we compare an economy with networks with an economy without, and if these two economies have the same unemployment rate, do networks increase the time needed by this subpopulation to converge towards the aggregate unemployment rate?

For that purpose, we simulate 1000 networks during 35 years (12775 periods). We assume that our economy is at the steady state. All these networks begin with no employee and we compute at each period the average unemployment rate in networks. We also simulate the evolution of this rate for 1000 groups of 40 individuals in an economy without network but with the same aggregate unemployment rate and the same values on the structural parameters $\{y, h, z, \beta, \alpha, r, q\}$. These forty workers are also assumed to be unemployed in the first period. Remember that, in this case, there is no correlation between agents' statuses. In the same way, the probability to get a job offer does not change over time and amounts to $M(v, u) / u$. The results for the economy without networks is used as a benchmark to quantify the unemployment persistence induce by networks, the average unemployment rate being given. The evolution of the unemployment rates is displayed in Figure 4 (we only display the first 15 years). We also provide the evolution of the ratio of networks' unemployment rate over the unemployment rate in the groups of 40 workers without social links. 

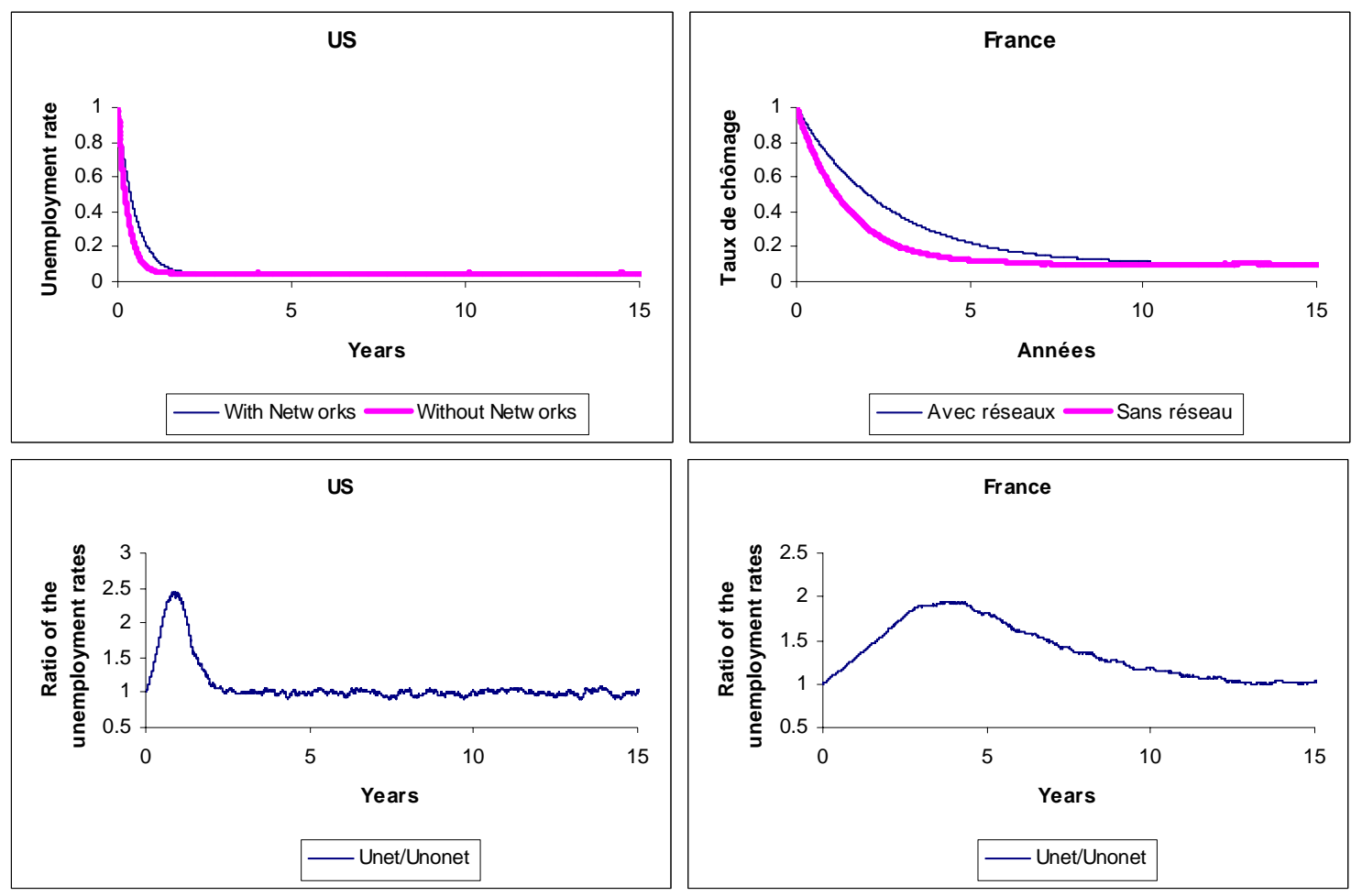

Figure 4 : Dynamics of the unemployment rate in networks initially without employees and the ratio of the unemployment rates. Unonet $=$ Unemployment rate in an economy without networks.

Unet $=$ unemployment rate in an economy with social links between workers.

Social networks induce unemployment persistence in the sense that the convergence of a subpopulation towards the aggregate unemployment rate is longer in an economy with networks than in an economy where workers do not use their friends and relatives to get job offers. In the US, convergence takes two and a half year with social networks, one and a half without. For France, convergence takes about fourteen years in the first case, seven years in the latter. Hence, convergence is about twice longer in a economy where workers are linked together, whatever the aggregate unemployment rate. Besides, during convergence, the unemployment rate in networks can be twice higher than in an economy of "disconnected" workers. It is worth noting that it is not due to differences in the vacancy rate. In our two economies, the vacancy rates are about the same ${ }^{10}$. However, previous reasonings have shown that networks induce congestion effects that are harmful for the unemployed in networks with few employees. We display in Figure 5, the probability for an unemployed to get a job offer in an economy with social networks and in an economy without.

\footnotetext{
${ }^{10}$ Fo example, for France, the vacancy rate in an economy with networks amounts to .1422, in an economy without .1428.
} 

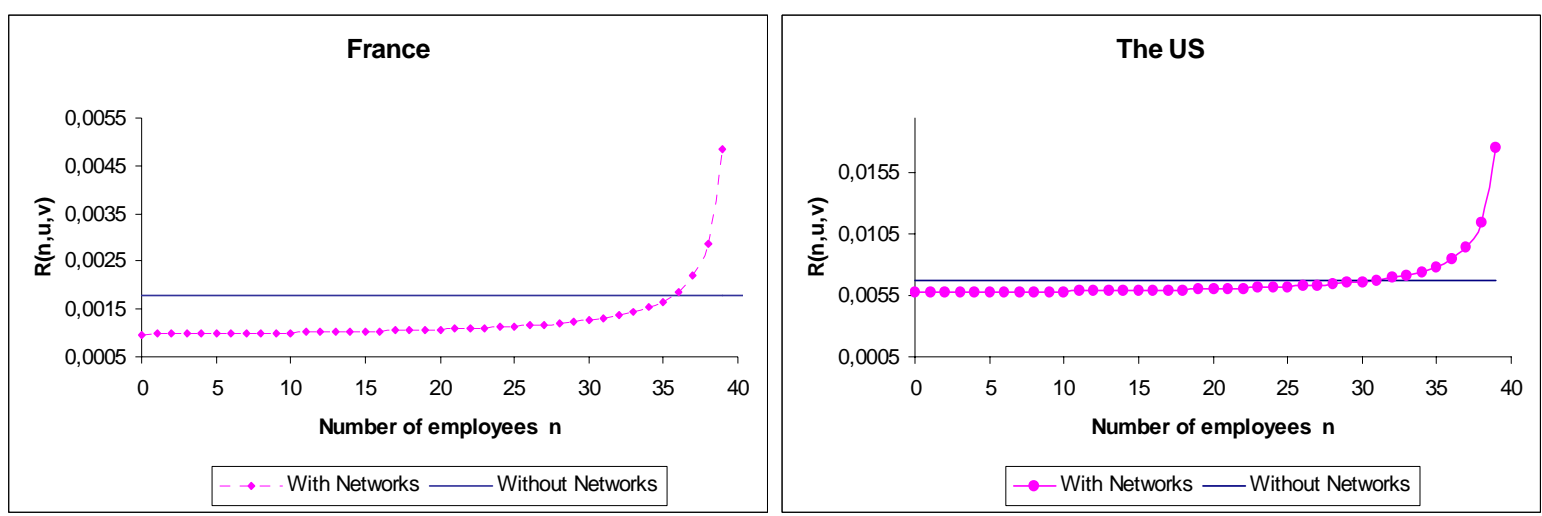

Figure 5: The exit rate from unemployment in an economy with networks and in an economy without, for France and the US.

In an economy where individuals cannot use their acquaintances to get a job, the exit rate from unemployment does not hinge on the number of employees in his neighborhood. On the contrary, in an economy where workers use their contacts, an unemployed in a network with high unemployment rate suffers from the congestion effect, while its network is ineffective in job search In this case, the state dependence of the exit rates slows down the convergence of this network toward the average unemployment rate. Nevertheless, let us remark that this is not necessary the case for networks with a sufficiently high employment rate. Indeed, for the US, the probability to get a job is higher with networks than in an economy without networks for networks with at least 30 employees (that is for an unemployment rate below 25\%). For these networks, the existence of social networks accelerate the increase of the employment rate.

In comparison with the papers of Calvo-Armengol and Jackson (2004a,b), our model shows that an endogenous matching technology is needed to study the impact of social networks on the labor market. The correlation between agents' statuses does not necessary induce "stickiness" in the employment dynamics. On the one hand, the individuals benefit from the search intensity of employees in their network. On the other hand, the fact that employees also search for a job (for their unemployed friend) entails an increase in congestions on the market. For a given network, the overall effect depends on the number of employees. For networks with a high unemployment rate, networks slow down the improvement of the network's state. For other networks with a sufficiently low unemployment rate, networks accelerates this improvement.

Eventually, let us remark that the link between networks, the aggregate unemployment rate and the matching technology is important if one try to quantify their effects. Even in the case where networks slow down the convergence, the quantitative impact can be quite small. Especially, for the US (see Figure 4), the formal channel for the information about job offers is sufficient to compensate the disadvantage of being embedded in an inefficient social network. On the contrary, social networks seem to be an important channel for unemployment persistence for a typical european continental economy. 


\section{Conclusion}

This paper provides a simple way to study the effect of social networks on the within group wage dispersion and unemployment persistence. In a framework where there is search frictions and where job arrival rate is endogenous, we derive the equilibrium distribution of unemployment rates across ex-ante identical networks. Since the probability to get a job offer increases with the number of employees in the networks, the existence of social networks induces wage dispersion when wages are the subject of bargaining. Our simulations show that networks induce significant wages inequalities.

Besides, contrary to the claim of Calvo-Armengol and Jackson (2004a,b), social networks do not necessary induce stickiness in unemployment dynamics. Our endogenous matching technology shows that the effects of networks on the dynamics mostly hinge on search externalities and not on the correlation between statuses. Networks can even accelerate the improvement of the unemployment rate of a subpopulation of workers. Our endogenous model allows us to quantify this unemployment persistence's channel. For the most disadvantaged networks, the convergence toward the aggregate unemployment rate is twice longer in an economy with social networks.

One of the main limit of our model is that we do not endogenize the search intensity of employees. Let us recall that, in our model, since there is no absorbing state, any network, whatever is present state, will pass through the average unemployment rate in a finite time (the next section analyses this dynamics). Hence, our results can be considered as a lower bound for the inequalities induced by the social networks. A framework with partial networks' endogeneity could worsen inequalities and induce strong persistence since employees could have an incentive to leave the most disadvantaged networks. An employee cooperates only if he knows that his relatives could be useful in the future in case of job loss and if the decrease in utility if unemployed is large. Consequently, the cooperation is no longer sustainable in social networks with low unemployment rate. Such a mechanism could create social exclusion traps. Besides, economic institutions such as unemployment subsidies could threaten cooperation by decreasing the loss of agents when unemployed. This issue in on our research agenda.

Eventually, let us notice, that the mechanism emphasized in this paper could be use to address a wide range a phenomenon. For example, empirical evidences point out that wages have an increasing but concave profile with the experience on the labor market (for a recent survey see Neal and Rosen, 2000). On the other hand, sociological studies (for a recent survey see Granovetter, 1995) demonstrate that social networks of young workers are often ineffective as regards job search since they mostly linked together young workers looking for a job. Consider in our model a social network of young workers. At the beginning of their working life nobody has a job and the informal channel is not effective to get job offers. With time, the number of employees increases and more offers are transmitted through the network. In the same way, the network's wages increase since the individual arrival rate of job offers is higher. 


\section{References}

Addison J. and P. Portugal, 2002, Job Search Methods and Outcomes, Oxford Economic Papers, 54, 505-533.

Admati A., Perry M., 1987, Strategic Delay in Bargaining, The Review of Economic Studies, 53 (3), 345-364.

Albrecht J., Gautier P. and S. Vroman (2003), Matching with multiple applications, Economics Letters, 78, pp. 67-70.

Bentolila S., C. Michelacci and J. Suarez, 2003, Social Contacts and Occupational Choice, mimeo.

Bernard H.R., Johnsen E.C., Kilworth, P.D., and S. Robinson, 1989, Estimating the size of an average personal network and of an event subpopulation, in M. Kochen (ed), The Small W orld, 159-175 (Norwood, N.J: Ablex)

Bernard H.R., Johnsen E.C., Kilworth, P.D., Shelley G. and C. McCarty, 2001, Estimating the Ripple Effect of a Disaster, Connections, 24, 30-34.

Boorman S.A., 1975, A Combinatorial Optimization Model for Transmission of Job Information Through Contact Networks, Bell Journal of Economics, 6, 216-249.

Bowlus A.J. (1997), "A Search Interpretation of Male-Female Wage Differentials", Journal of Labour Economics, 15, 625-657.

Cahuc P. and F. Fontaine, 2003, On the efficiency of Job Search with Social Networks, CEPR Discussion Paper $n^{\circ} 3511$. www.cepr.org or eurequa.univ-paris1.fr/membres/fontaine/.

Calvo-Armengol A. and M. Jackson (2004a), "The Effects of Social Networks on Employment and Inequality", American Economic Review, 94(3), 426-454.

Calvo-Armengol A. and M. Jackson, 2004b, Networks in Labor Market: Wage and Employment Dynamics and Inequality, mimeo, masada.hss.caltech.edu/ ${ }^{\sim}$ jacksonm/Jackson.html.

Calvo-Armengol A. and Y. Zenou, 2002, Job-Matching, Social Network and Word-of-Mouth Communication, CEPR working paper, $\mathrm{N}^{\circ}$ 2797. www.cepr.org.

Campbell K. and P. Mardsen, 1990, Recruitment and Selection Processes: The Organizational Side of Job Searches, in: R. Breiger, ed., Social Mobility and Social Structure, New York: Cambridge University Press, 59-79.

Cramton P., 1992, Strategic Delay in Bargaining with Two-Sided Uncertainty, The Review of Economic Studies, 59, 205-225.

Crépon B., Deniau N., and S. Pérez-Duarte, 2002, Wages, Productivity, and Worker Characteristics: A French Perspective, CREST Working Paper.

Dutta B., Ghosal S. and Ray D., 2005, Farsighted network formation, Journal of Economic Litterature, 122 (2), 143-164.

Fernandez R.M., Castilla E.J. and P. Moore, 2000, Social Capital at Work : Networks and Employment at a Phone Center, American Journal of Sociology, 105, 1288-1356.

Fontaine F., 2004, Do Workers Really Benefit from their Social Netwoks?, IZA DP n¹282, eurequa.univ-paris1.fr/membres/fontaine/.

Glaeser E., 2000, Non Market Iteractions, NBER Working Paper, N${ }^{\circ} 053$, www.nber.org.

Granovetter M., 1995, Getting a Job: A Study of Contacts and Careers, $2^{\text {nd }}$ edition (Harvard University Press, Cambridge).

Gregg P. and J. Wadsworth, 1996, How Effective Are State Employment Agencies? Jobcentre Use and Job Matching in Britain, Oxford Bulletin of Economics and Statistics, 58, 43-67. 
Hamermesh D., 1993, Labor Demand, Princeton University Press.

Gul G., Sonnenschein H., On Delay in Bargaining with One-Sided Uncertainty, Econometrica, $56(3), 601-611$.

Hansen S. and G. Pratt, 1991, Job Search and the Occupational Segregation of Women, Annals of the Association of American Geographers 81 (2), 229-253.

Hellerstein J.K., Neumark D., and K.R Troske, 1999, Wages, Productivity, and Worker Characteristics: Evidence from Plant-Level Production Functions and Wage Equations, Journal of Labor Economics, 17, 409-446.

Holzer H., 1987, Hiring Procedures in the Firm: Their Economic Determinants and Outcomes, in: M. Kleiner, ed., Human Ressources and the Performance of the Firm, Wis.: Industrial Relation Research Association, 243-274.

Holzer H., 1988, Search Methods Used by Unemployed Youth, Journal of Labor Economics, 6, $1-21$.

Hosios D., 1990, On the Efficiency of Matching and Related Models of Search and Unemployment, Review of Economic Studies, 57, 279-298.

Jackson M. and A. Watts, 2002, The Evolution of Social And Economic Networks, Journal of Economic Theory, 106 (2), 265-295.

Kugler A., 2003, Employee Referrals and Efficiency Wages, Labour Economics, 10 (5), 531-556. Montgomery D., 1991, Social Networks and Labor Market Outcomes: Towards an Economic Analysis, American Economic Review, 81, 1408-1418.

Mortensen D., 2003, Wage Dispersion : Why Are Similar Workers Paid Differently? (MIT Press, Cambridge).

Mortensen D. and C. Pissarides, 1999, "Job Reallocation, Employment Fluctuations and Unemployment", in Woodford, M. and J. Taylor (eds), Handbook of M acroeconomics, Elsevier Science Publisher.

Neal D. and S. Rosen, 2000, "Theories of the Distribution of Earnings", A. B. Atkinson and F. Bourguignon (eds), Handbook of income distribution, pp. 379-427, Elsevier Science Publisher.

Page F., Wooders M. and Kamat S., 2005, Networks and farsighted stability, Journal of Economic Litterature, 120 (2), 257-269.

Petersen T., Saporta I. and M.D. Seidel, 2000, Offering a Job: Meritocracy and Social Networks, American Journal of Sociology, 106, 763-816.

Petrongolo B. and C. Pissarides, 2001, Looking into the Blackbox: A Survey of the Matching Function, Journal of Economic Literature, 39, 390-431.

Postel-Vinay F., Robin J-M., 2002, Equilibrium Wage Dispersion with Worker and Employer Heterogeneity, Econometrica, 70, 2295-2350.

Pissarides C., 2000, Equilibrium unemployment theory, 2nd edition (Cambridge, MIT Press).

Rees A., 1966, Information Networks in Labor Markets, American Economic Review, 56, 559566 .

Simon C and J. Warner, 1992, Matchmaker, Matchmaker: The Effect of Olf Boy Networks on Job Match Quality, Earnings and Tenure, Journal of Labor Economics, 10, 306-330.

Topa G., 2000, Social Interactions, Local Spillovers and Unemployment, Review of Economic Studies, 68, 261-295.

Van den Berg G.J. and A. van Vuuren, 2001, The Effect of Search Frictions on Wages, mimeo Free University of Amsterdam.

Waldinger R., 1997, Social Capital or Social Closure? Immigrant Networks in the Labor Market, Lewis Center for Regional Policy Studies Working Paper Series. 
Watts D.J., 1999, Small Worlds - The Dynamics of Networks between Order and Randomness, Princeton University Press. 


\section{Appendix}

\section{An example of an urn-ball process with social networks}

This scenario borrows from Albrecht et al. (2003) urn-ball model but with social networks.. Consider an economy with $V$ advertised vacancies and $U$ unemployed workers. By assumption, unemployed workers and employees are looking for a job, but the employees for their unemployed friends. However, we assume that, at each period, only some workers are actively looking for a job. We denote $s_{u}$ the probability for the unemployed workers to be active, $s_{e}$ for the employees. A job offers is represented by a ball which is sent into the active urns, i.e. the workers doing search effort. We assume that every active worker has the same probability to get a job offer. According to this scenario, there are $V$ balls (job offers) and $U s_{u}+(N-U) s_{e}$ urns at each period.

The number of job offers received by a given job seeker follows a binomial distribution $B\left(V,\left(U s_{u}+(N-U) s_{e}\right)^{-1}\right)$. The aggregate number of job seekers who receive at least one offer reads

$$
M=\left(U s_{u}+(N-U) s_{e}\right)\left[1-\left(1-\frac{1}{U s_{u}+(N-U) s_{e}}\right)^{V}\right]
$$

For a large number of job offers and a large number of unemployed, this binomial distribution can be approximated by a Poisson distribution $P(\theta)$, with $\theta=V /\left(U s_{u}+(N-U) s_{e}\right)$ the labor market tightness. Thus, the probability a match for a job offer $M / V$ can be approximated by

$$
m(\theta)=\frac{1}{\theta}(1-\exp (-\theta))
$$

Thus we have $M \approx V m(\theta)$, i.e. the matching function exhibits approximate constant return to scale.

Besides

$$
\partial m(\theta) / \partial \theta=(\theta \exp (-\theta)-1+\exp (-\theta)) / \theta^{2}
$$

which is negative as long as $1-\exp (-\theta)>\theta \exp (-\theta)$. Remark that $1-\exp (-x)-x \exp (-x)=0$ when $x=0$ and that the derivative of this function with respect to $x$ is positive for $x>0$. Hence $\partial m(\theta) / \partial \theta<0$. 


\section{The effect of network's size}
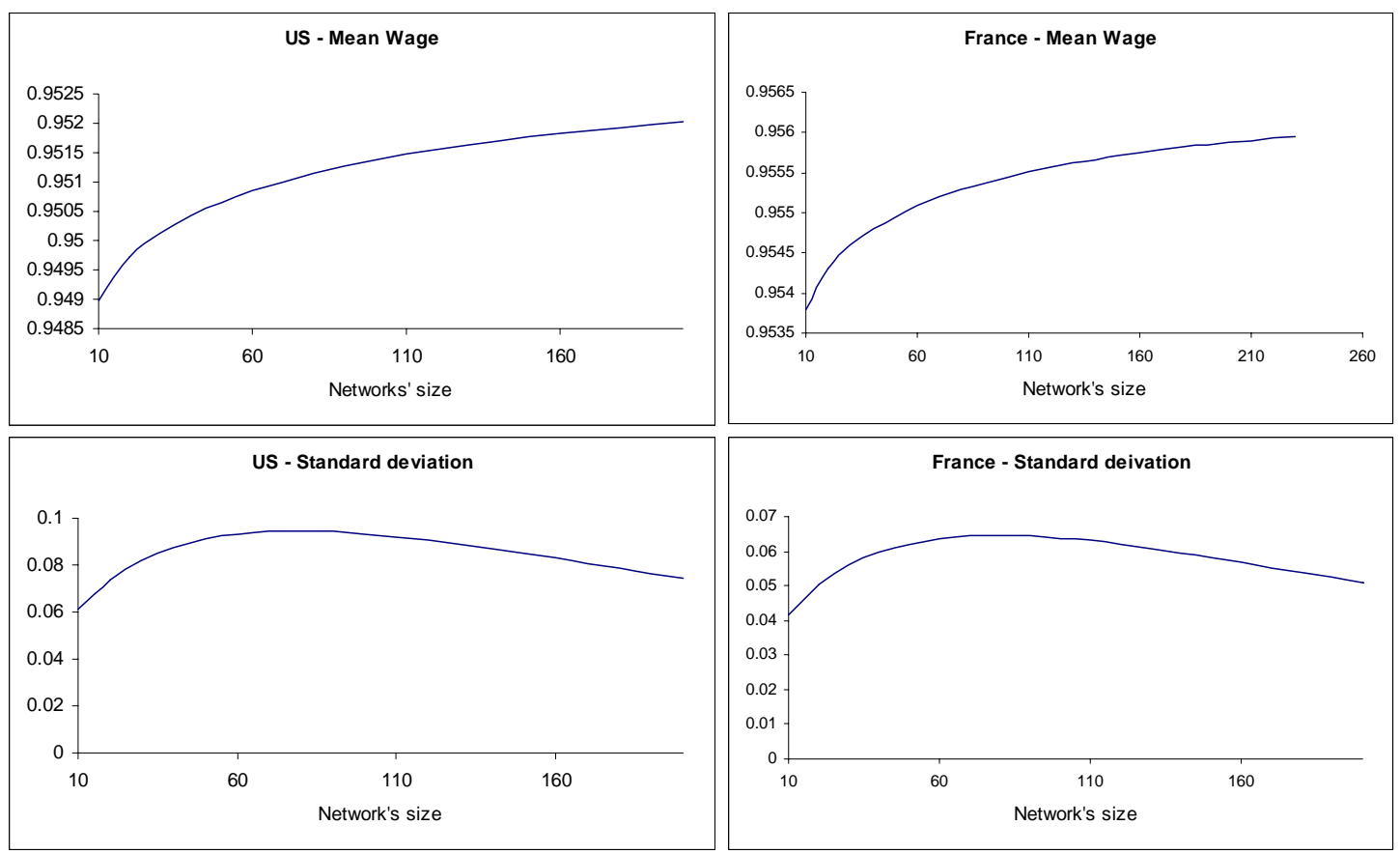

Figure 5: The effect of the networks' size (US economy).

From the point of view of the efficiency of the labor market, larger networks better the matching technology. For the United States, the mean of the wage distribution goes from .90 to .95 when the network's size $\ell$ rises from 10 to 200 . However, for the chosen values on parameters, an increase in $\ell$ has an ambiguous effect on wage dispersion. For the most disadvantaged networks, an rise in the number of acquaintances entails an increase in the number of unemployed who compete for the offers transmitted by the employees. Indeed, taken $u$ as given, $R(n, u, v)$, the individual arrival rate of job offers, decreases with network's size. For a given network, this effect is counterbalanced only if the number of employees increases sufficiently. Consequently, as $\ell$ goes up, the wage gap between networks in different state can become wider. However, in the long run, larger networks limit the probability to be in networks with low employment rate. In the limit case where there is a unique network $(\ell=N)$, all unemployed face the same job arrival rate and there is no wage dispersion. 